\title{
Erratum to: Cultural Causations and Expressions of Distress: a Case Study of Buufis Amongst Somalis in Johannesburg
}

\section{Zaheera Jinnah ${ }^{1}$}

Published online: 26 December 2016

(C) Springer Science+Business Media Dordrecht 2016

\section{Erratum to: Urban Forum \\ DOI: $10.1007 / \mathbf{s 1 2 1 3 2 - 0 1 6 - 9 2 8 3 - y}$}

The original version of this article unfortunately contained a mistake in the article title.

The word caste in the article title should have been case. The corrected article title is shown above.

The original article was corrected.

The online version of the original article can be found at doi:10.1007/s12132-016-9283-y.

1 African Centre for Migration and Society, University of the Witwatersrand, Johannesburg, South Africa 